\title{
HBV DNA integrates into upregulated ZBTB20 in patients with hepatocellular carcinoma
}

\author{
ZEBAO HE ${ }^{1}$, JIANSHENG ZHU ${ }^{1}$, JINGGANG MO ${ }^{2}$, HAIHONG ZHAO ${ }^{1}$ and QIUYUE CHEN ${ }^{2}$ \\ ${ }^{1}$ Department of Neurology, Taizhou Enze Medical Center Enze Hospital; ${ }^{2}$ Department of Neurology, \\ Taizhou Central Hospital, Taizhou University Hospital, Taizhou, Zhejiang 318000, P.R. China
}

Received October 9, 2019; Accepted March 18, 2020

DOI: $10.3892 / \mathrm{mmr} .2020 .11074$

\begin{abstract}
Hepatitis B virus (HBV) affects the malignant phenotype of hepatocellular carcinoma (HCC). The aim of the present study was to investigate the integration sites of $\mathrm{HBV}$ DNA and the expression of the zinc finger protein, zinc finger and BTB domain containing 20 (ZBTB20) in patients with hepatocellular carcinoma. Integration of the HBV gene was detected using a high-throughput sequencing technique based on the HBV-Alu-PCR method. The expression of ZBTB20 was detected by western blotting. HBVX integration sites were detected in $\sim 70 \%$ of the HCC tissue samples. HBV-integrated subgene $\mathrm{X}$ detection suggested that $67 \%$ of the integrated specimens were inserted into the host $\mathrm{X}$ gene in a forward direction, $57 \%$ in a reverse direction, $24 \%$ in both forward and reverse directions, and $38 \%$ had two $\mathrm{HBV}$ integration sites. A total of 3,320 HBV integration sites were identified, including 1,397 in HCC tissues, 1,205 in paracancerous tissues and 718 in normal liver tissues. HBV integration fragments displayed enrichment in the 200-800 bp region. Additionally, the results suggested that $\mathrm{HBV}$ was highly integrated into transmembrane phosphatase with tensin homology, long intergenic non-protein coding RNA (LINC)00618, LOC101929241, ACTR3 pseudogene 5, LINC00999, LOC101928775, deleted in oesophageal cancer 1, LINC00824, EBF transcription factor 2 and ZBTB20 in tumour tissues. Furthermore, the expression of ZBTB20 was upregulated in HCC tissues compared with normal control liver tissues, and was associated with HBV integration frequency. The present study suggested that HBV DNA integrated into upregulated ZBTB20 in patients with hepatocellular carcinoma, which might promote the occurrence and development of HCC. Furthermore, the results of the present study may provide a theoretical basis for the diagnosis and treatment of HCC.
\end{abstract}

Correspondence to: Dr Qiuyue Chen, Department of Neurology, Taizhou Central Hospital, Taizhou University Hospital, 999 Donghai Road, Taizhou, Zhejiang 318000, P.R. China

E-mail: qiu154@126.com

Key words: hepatocellular carcinoma, hepatic B virus, HBV integration, zinc finger and BTB domain containing 20

\section{Introduction}

Hepatocellular carcinoma (HCC) is the third leading cause of cancer-associated death worldwide $(1,2)$. Approximately $85 \%$ of HCC cases occur in developing countries, with the majority of cases occurring in Africa and Asia (3). Hepatitis B virus (HBV) is a small DNA virus with a full length of 3,200 bp. HBV affects the malignant phenotype of HCC by increasing chromosome instability and promoting cell proliferation (4). The carcinogenic mechanism of HBV is extremely complex and is not completely understood (5). Further investigation into the mechanism underlying HCC development associated with HBV could aid with the identification of novel therapeutic strategies for HCC (6).

HBV infection is currently considered to be a high risk factor for primary $\mathrm{HCC}(7,8)$. Persistent $\mathrm{HBV}$ infection can lead to chronic liver disease and accounts for $\sim 50 \%$ of all HCC cases (7). In China, $>80 \%$ of patients with HCC have chronic $\mathrm{HBV}$ infection, and patients with $\mathrm{HBV}$ have a $\geq 300$-fold increased risk of developing primary HCC (9). HBV contains four overlapping open reading frames: $S$ region (surface protein HBS encoding the virus), $\mathrm{P}$ region (polymerase protein encoding the virus), $\mathrm{X}$ region ( $\mathrm{X}$ protein encoding the virus, $\mathrm{HBX}$ ) and pre $\mathrm{C}$ region (encoding the viral e and $\mathrm{c}$ antigens) $(5,10,11)$. HBV DNA can integrate into host genes, altering chromosomal instability and the function of endogenous genes, thereby inducing $\operatorname{HCC}(8,12,13)$. Since the initial discovery of HBV DNA integration by Edman et al (14) in 1980, the association between HBV DNA integration and the pathogenesis of HCC has become a key research topic. The HBV integration mechanism has been explored by a number of research teams, including teams based at the University of Hong Kong, the National University of Singapore, the Shenzhen University of China Genetics Research Institute, and the Asian Cancer Research Organization, with the aim of producing a highly precise, unbiased HBV integration map (15-17). Genome wide sequencing of cancer and paracancerous tissue samples from $81 \mathrm{HBV}$-positive patients with $\mathrm{HCC}$ and $7 \mathrm{HBV}$-negative patients with HCC suggested that HBV integration was a common phenomenon in HCC. Furthermore, the study reported that the frequency of HBV integration was significantly higher in tumor tissues $(86.4 \%)$ compared with adjacent normal tissues (30.7\%) (18). 
The zinc finger protein ZBTB20 is a novel transcriptional repressor $(19,20)$. ZBTB20 contains a conserved BTB domain at the N-terminus, which typically mediates protein interactions, and five conserved $\mathrm{C} 2 \mathrm{H} 2$ zinc finger domains at the C-terminus, which result in postnatal transcriptional loss of the AFP gene in the liver (21). Previous studies have reported that liver-specific ZBTB20 knockout mice display high liver AFP expression; however, the liver tissue structure is normal and hepatocytes remain in a normal resting state. These findings suggested that there was not an intrinsic relationship between hepatocyte AFP expression and cell proliferation $(21,22)$. Therefore, at present, it is unclear whether HBV DNA integrates into the zinc finger protein ZBTB20.

The aim of the present study was to identify the HBV DNA integration site and investigate the expression of ZBTB20 in HCC tissues of patients with chronic HBV and HCC. The results of the present study may provide a basis for the diagnosis and treatment of HCC.

\section{Materials and methods}

Specimens. A total of 30 patients with HCC (age, 45-75 years; median age, $57.07 \pm 7.83$ years; 23 male and 7 female; 22 cases of stage II and 8 cases of stage III) were recruited from Taizhou Enze Medical Center Enze Hospital between September 2017 and July 2019. The patients were diagnosed by clinical and pathological examination in accordance with the Guidelines for Prevention and Treatment of Chronic HBV (2015 edition) (23). None of the participants had received any anticancer or antiviral treatment prior to the study, and were serum HBsAg-positive. Patients with other viral infections, who had a drug addiction or who were alcoholics, or who had autoimmune hepatitis were excluded. HCC, paracancerous $(\leq 2 \mathrm{~cm}$ from the edge of the tumor) and normal control $(\geq 5 \mathrm{~cm}$ from the edge of the tumor) tissues were obtained from patients with HCC by surgical resection at the Taizhou Enze Medical Center Enze Hospital. All tissue samples were cut into $0.5 \mathrm{~cm}^{3}$ slices, frozen in liquid nitrogen and stored at $-80^{\circ} \mathrm{C}$ until further analysis. The present study was approved by the Ethics Committee of Taizhou Central Hospital (approval no. T13010123Y), and written informed consent was obtained from each patient.

DNA extraction. HCC, paracancerous and normal control tissues $\left(0.027-0.125 \mathrm{~cm}^{3}\right)$ were cut. Following the addition of $400 \mu 1$ OmniPur DNA extraction buffer (EMD Millipore), the tissues were homogenized in a tissue homogenizer and rinsed with $100 \mu 1$ DNA extraction buffer. The resulting solution was mixed with $100-200 \mu \mathrm{g} / \mathrm{ml}$ proteinase $\mathrm{K}$ in a $37^{\circ} \mathrm{C}$ water bath for 5-12 h, mixed with $500 \mu \mathrm{l}$ equilibrated phenol, and centrifuged at $11,180 \mathrm{x} \mathrm{g}$ for $1 \mathrm{~min}$ at $4^{\circ} \mathrm{C}$. The supernatant was collected, mixed with $500 \mu \mathrm{l}$ chloroform and centrifuged at $11,180 \mathrm{x} \mathrm{g}$ for $1 \mathrm{~min}$ at $4^{\circ} \mathrm{C}$. The supernatant was collected, mixed with $60 \mu \mathrm{l} \mathrm{NaOAc}(3 \mathrm{M} ; \mathrm{pH} 4.8)$ and $1,000 \mu \mathrm{l}$ ice-cold ethanol at $-20^{\circ} \mathrm{C}$ for $2 \mathrm{~h}$, and centrifuged at $21,912.8 \mathrm{x}$ g for $15 \mathrm{~min}$ at $4^{\circ} \mathrm{C}$. Subsequently, the supernatant was discarded and the pellet was washed with pre-cooled $70 \%$ ethanol, dried, dissolved in double-distilled water, and stored at $-20^{\circ} \mathrm{C}$ until further analysis. DNA concentration was quantified by spectrophotometry at an absorbance of $260 \mathrm{~nm}$.
HBV-Alu-PCR amplification reaction. The primers used for PCR amplification are presented in Table I. The amplification primers used for the first round of HBV-Alu-PCR amplification were pUTP and UP5. The total reaction volume $(300 \mu \mathrm{g}$ DNA in $25 \mu \mathrm{l}$ ) consisted of $2.5 \mu \mathrm{l}$ EX-Taq DNA polymerase (Thermo Fisher Scientific, Inc.), $2 \mu 12.5 \mathrm{mmol} / 1 \mathrm{NTP}, 1 \mu 1$ $10 \mu \mathrm{mol} / 1$ primer, $1 \mu \mathrm{l} 1 \mathrm{U}$ EX Taq DNA polymerase and

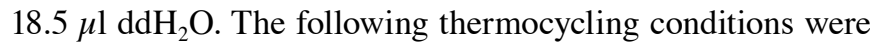
used for the first round of PCR amplification: Pre-denaturation at $94^{\circ} \mathrm{C}$ for $1 \mathrm{~min}$, followed by 10 cycles of denaturation at $94^{\circ} \mathrm{C}$ for $30 \mathrm{sec}$, annealing at $59^{\circ} \mathrm{C}$ for $30 \mathrm{sec}$, and $70^{\circ} \mathrm{C}$ extension for $1 \mathrm{~min}$, set 30 cycles and at the end of procedure $70^{\circ} \mathrm{C}$ extension for $5 \mathrm{~min}$. Subsequently, $0.5 \mathrm{U}$ uracil DNA glycosidase was added to the system at $37^{\circ} \mathrm{C}$ for $30 \mathrm{~min}$ to disrupt the dUTP-containing DNA. The reaction was stopped by an incubation at $94^{\circ} \mathrm{C}$ for $10 \mathrm{~min}$. Subsequently, the MM37 and UP6 (10 $\mu \mathrm{mol} / 1 ; 1 \mu \mathrm{l}$ each) primers were added to the PCR system for the second round of PCR amplification, using the following thermocycling conditions: Pre-denaturation at $94^{\circ} \mathrm{C}$ for $1 \mathrm{~min}$; followed by 40 cycles of denaturation at $94^{\circ} \mathrm{C}$ for $30 \mathrm{sec}$ and annealing from $65-55^{\circ} \mathrm{C}$ for $30 \mathrm{sec}$ (the temperature decreased by $1^{\circ} \mathrm{C}$ for the first 10 cycles and was maintained at $55^{\circ} \mathrm{C}$ for the last 20 cycles); and a final extension at $72^{\circ} \mathrm{C}$ for $3 \mathrm{~min}$. Subsequently, for the third round of PCR amplification, $1 \mu \mathrm{l}$ PCR product was used as a template, and MM60 and UP6 primers were used in a $50 \mu \mathrm{l}$ amplification system (as with the first round, above) following the thermocycling conditions used for the second round of PCR amplification.

DNA sequencing. The PCR products obtained following the third round of PCR amplification were confirmed by $1 \%$ agarose gel electrophoresis and visualized by ethidium bromide using a $2500 \mathrm{Gel}$ Imaging system (Tanon Science \& Technology Co., Ltd.). Subsequently, DNA purification by QIAquick PCR Purification kit (Qiagen $\mathrm{GmbH}$ ) and sequencing were performed. Sequencing was performed using an ABI-3730XL fully automated sequencer (Applied Biosystems; Thermo Fisher Scientific, Inc.). Sequence analysis and information regarding the sequencing of HBV DNA localized on human chromosomes was retrieved using the National Center for Biotechnology Information (NCBI) Basic Local Alignment Search Tool (BLAST 2.6.0+; www. ncbi.nlm.nlh.gov/BLAST), NCBI Map Viewer v2018 (www. ncbinlm.nih.gov/mapview) and University of California Santa Cruz BLAST-like Alignment Tool (samtools 1.2-99-ge2bb18f, www.genome.ucsc.edu/cgi bin/hgBlat).

$H B V D N A$ trapping and analysis of the $H B V$ integration site. Based on the $8 \mathrm{HBV}$ genotypes (A-H), their reported subtypes and the mutant information available in the Genome Information Broker for Viruses database release 1.0 (24), the HBV capture probe was designed using the MyGenostics algorithm (BED tools 1.119, Beijing MyGenostics Co., Ltd.). Genomic DNA fragments from HCC, paracancerous and normal control tissues (cut to 150-200 bp) were purified, mixed with a polyA tail, ligated, and linked to connector sequences to identify sequences for the construction of the basic sequencing library. After the hybridization library was captured and enriched by magnetic beads with an HBV DNA probe at $47^{\circ} \mathrm{C}$ for $24 \mathrm{~h}$, the unbound fragments were removed. The magnetic 
Table I. Primer sequences used for HBV-Alu-PCR amplification.

\begin{tabular}{llll}
\hline Name & \multicolumn{1}{c}{ Primer sequence } & HBV location (bp) & \multicolumn{1}{c}{ Annotation } \\
\hline MM37 & 5'-TGCCAAGTGTTTGCTGACGC-3' & $1,174-1,193$ & HBVX \\
UP5 & 5'-CAGUGCCAAGUGUUUGCUGACGCCAAAGUGCUGGGAUUA-3' & & Alu-forward \\
UP6 & 5'-CAAGTGGCTGACGCCAAAG-3' & & Alu-forward (Tag) \\
pUTP & 5'-ACAUGAACCUUUACCCCGUUGC-3' & $1,131-1,152$ & HB1 (HBVX) \\
MM60 & 5'-CTGCCGATCCATACTGCGGAAC-3' & $1,258-1,279$ & HB3 (HBVX) \\
\hline
\end{tabular}

HBV, hepatitis B virus; HBVX, Hepatitis B Virus Protein X; HB1, Hepatitis B Virus Protein 1; HB2, Hepatitis B Virus Protein 2; and HB3, Hepatitis B Virus Protein 3.
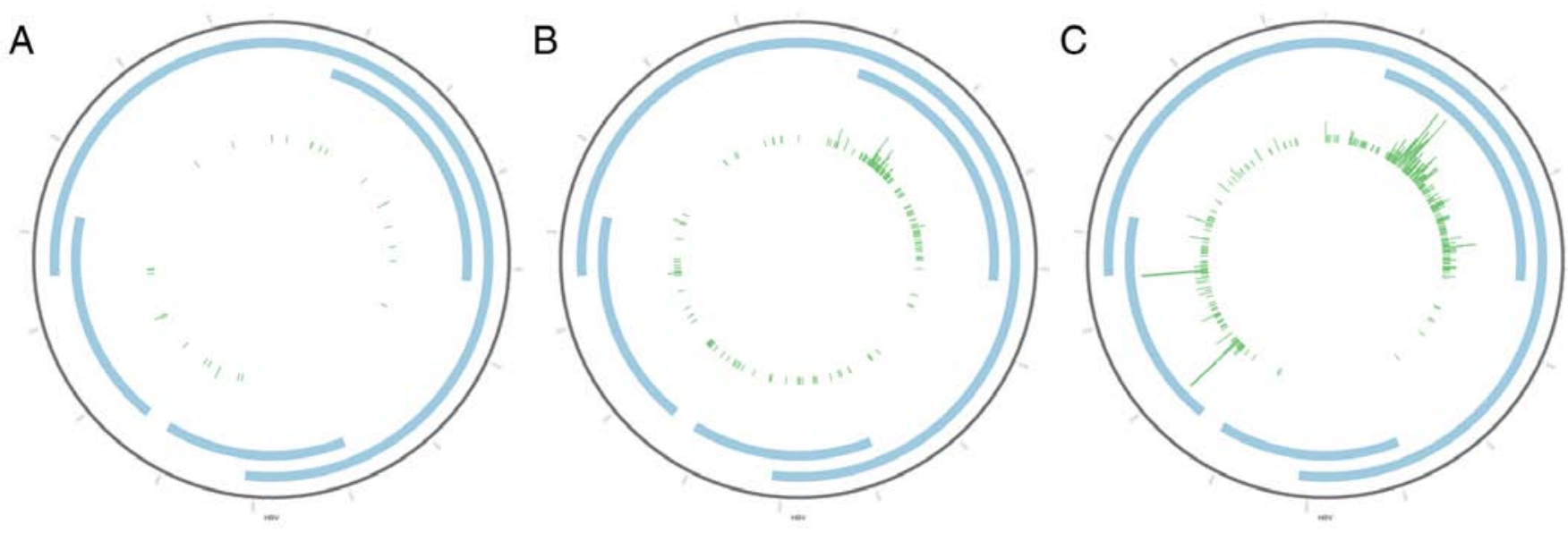

Figure 1. Circos plots of HBV break sites. HBV break sites in (A) normal, (B) paracancerous and (C) HCC tissues. The black circle indicates the length of the gene and the blue circle indicates open reading frames. Green columns indicate the break sites, and the column height indicates the frequency at which the break occurs. HBV, hepatitis B virus; HCC, hepatocellular carcinoma.

bead enriched fragments were eluted and amplified o generate a sequencing library. The KAPA-DNA polymerase (KAPA Biosystems) with primers (F: AATGATACGGCGACCA CCGAGATCTACACTC TTTCCCTACACGACGCTCTTC CGATC; R: CAAGCAGAAGACGGCATACGAGATNNNN NNNNGTGACTGGAGTTCAGACGTGTGCTCTTCCGAT) was used with the following thermocycling conditions: Pre-denaturation at $98^{\circ} \mathrm{C}$ for $45 \mathrm{sec}$; followed by 8 cycles of denaturation at $98^{\circ} \mathrm{C}$ for $15 \mathrm{sec}$ and annealing at $65^{\circ} \mathrm{C}$ for $30 \mathrm{sec}$ and $72^{\circ} \mathrm{C}$ for $30 \mathrm{sec}$; and a final extension at $72^{\circ} \mathrm{C}$ for $1 \mathrm{~min}$. The raw read data were obtained on a Hiseq 2000 Sequencing Platform (Illumina, Inc.), and clean data were generated by quality control and de redundancy processing. Positive HBV integration was defined as DNA fragments containing both a human genome sequence and an HBV sequence. According to the HBV integration sites obtained, the corresponding specimens were selected for PCR amplification and verified by Sanger sequencing. The KAPA-DNA polymerase (KAPA Biosystems) with primers (F: AATGAT ACGGCGACCACCGA; R: CAAGCAGAAGACGGCAT ACG) was used with the following thermocycling conditions: Pre-denaturation at $95^{\circ} \mathrm{C}$ for $4 \mathrm{~min}$; followed by $10-12$ cycles of denaturation at $98^{\circ} \mathrm{C}$ for $20 \mathrm{sec}$ and annealing at $58^{\circ} \mathrm{C}$ for $30 \mathrm{sec}$ and $72^{\circ} \mathrm{C}$ for $30 \mathrm{sec}$; and a final extension at $72^{\circ} \mathrm{C}$ for 5 min. Reads that completely overlapped with the HBV refer- ence sequence were removed, and other fusion reads were retained; the sequences were then assembled as paired end (PE) reads. Subsequently, the Burrows-Wheeler Aligner (BWA) software (v. 0.7.12-r1044; http://bio-bwa.sourceforge. net/) was used to align the PE reads with the human reference sequence and HBV reference sequence to complete the annotation. Reads with both a human genome sequence and an HBV sequence indicated a HBV integration site.

Western blot analysis. HCC, paracancerous and normal control tissues were lysed on ice in $50 \mathrm{mM}$ Tris- $\mathrm{HCl}(\mathrm{pH} 7.4)$, $150 \mathrm{mM} \mathrm{NaCl}, 1 \mathrm{mM}$ EDTA, $1 \mathrm{mM} \mathrm{Na} \mathrm{VO}_{4}, 1 \mathrm{mM} \mathrm{NaF}$, $1 \%$ Nonidet P-40, $0.25 \%$ sodium deoxycholate, $1 \mathrm{mM}$ PMSF, $1 \mathrm{mg} / \mathrm{ml}$ aprotinin and $1 \mathrm{mg} / \mathrm{ml}$ pepsin inhibitor. Proteins $(20 \mu \mathrm{g})$ were quantified using a BCA kit (Beyotime Institute of Biotechnology), separated via SDS PAGE (10\% gels) and transferred to PVDF membranes. The membranes were blocked in $5 \%$ non-fat milk at $25^{\circ} \mathrm{C}$ for $1 \mathrm{~h}$. Subsequently, the membranes were incubated with a primary antibody targeted against ZBTB20 (cat. no. ab48889; 1:500; Abcam) at $4^{\circ} \mathrm{C}$ overnight. Following primary incubation, the membranes were incubated with a HRP conjugated secondary antibody (ZB-2305; 1:10,000; OriGene Technologies, Inc.) at $25^{\circ} \mathrm{C}$ for $1 \mathrm{~h}$. Protein bands were visualized using an ECL immunoreactive western blot detection reagent (Pierce; Thermo Fisher Scientific, Inc.). 

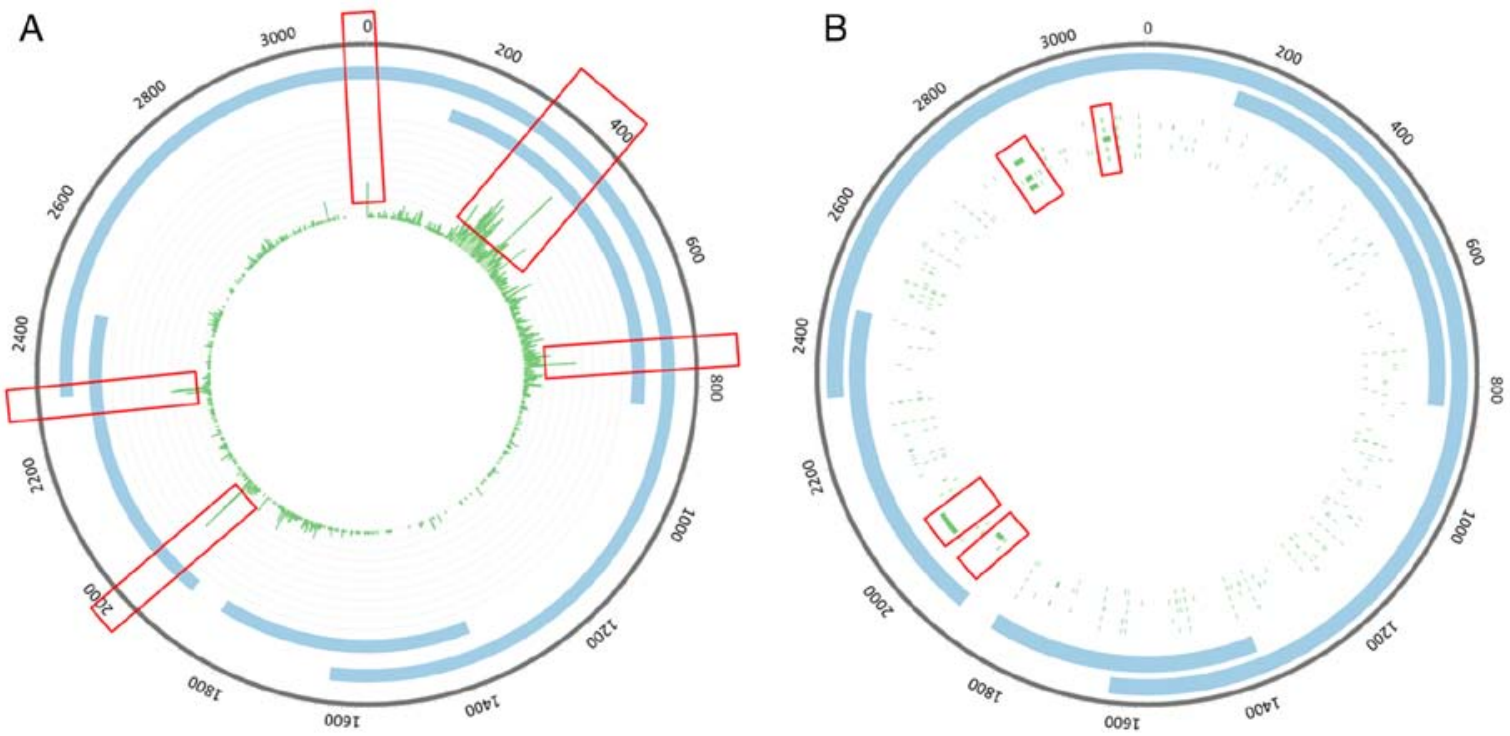

Figure 2. Distribution of integration sites in the hepatitis B virus genome. (A) Integration sites. Green columns indicate the break sites and the column height indicates the frequency at which the break occurs. (B) Mutation sites. Green blocks indicate the mutation sites and the size of the block indicates the integration frequency. The black circle indicates the length of the gene and the blue circle indicates the open reading frames.

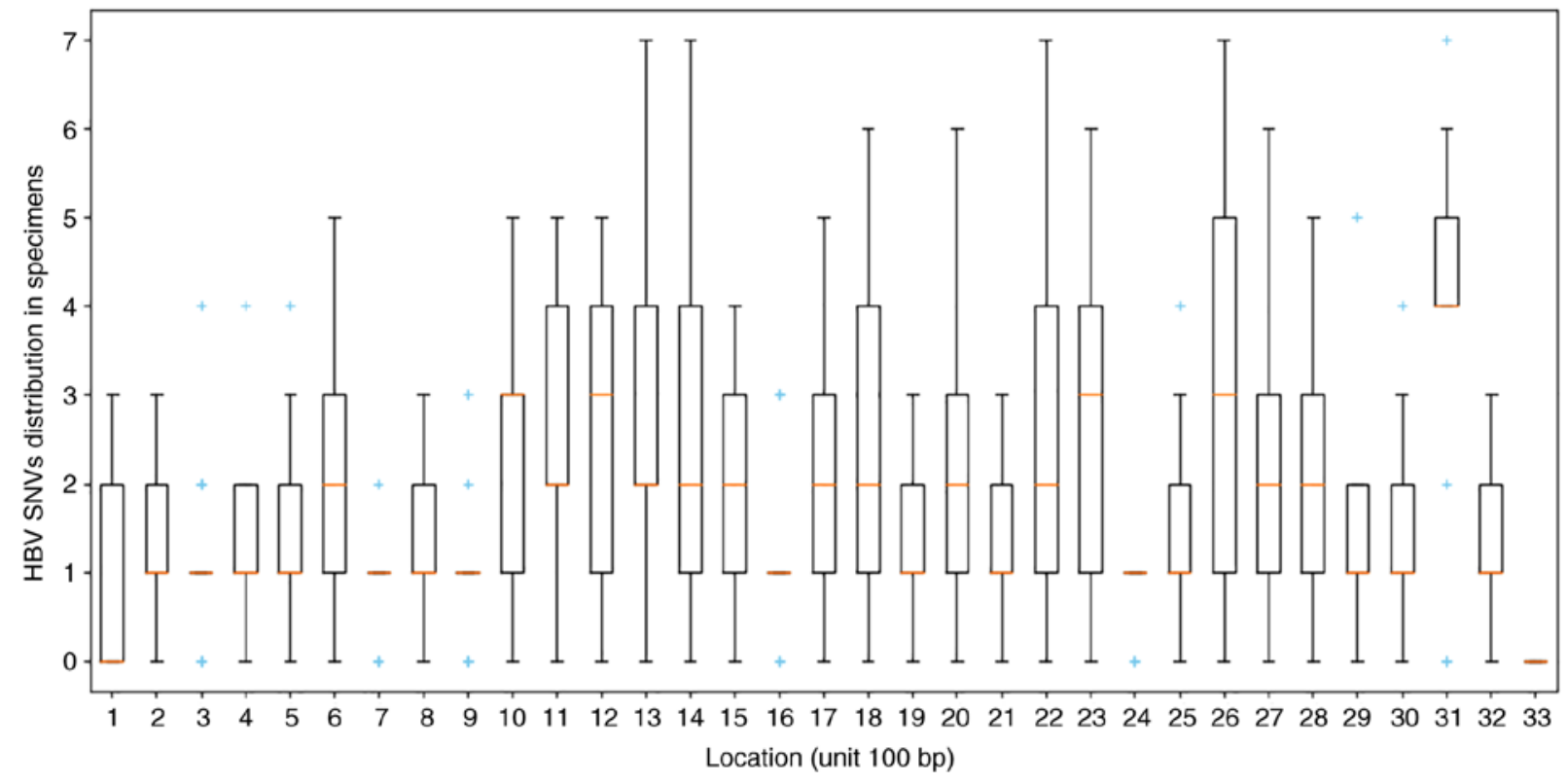

Figure 3. Distribution of mutation sites in the HBV genome. HBV, hepatitis B virus; SNV, single nucleotide variations.

$\beta$-actin (CW0096; 1:1,000, CoWin Biosciences) was used as the loading control. ImageJ (1.4.3.67, National Institutes of Health) was used for densitometry.

Statistical analysis. Statistical analyses were performed using SPSS software (version 19.0; IBM Corp.). Data were presented as mean \pm SD and analysed using one way ANOVA followed by the least significant difference post hoc-test. $\mathrm{P}<0.05$ was considered to indicate a statistically significant difference.

\section{Results}

$H B V X$ DNA integration sequences. Among the HCC tissues assayed by HBV-Alu-PCR, HBV integration sites were identi- fied in $\sim 70 \%$ of them (21/30; data not shown). Detection of HBV integrated with subgene $\mathrm{X}$ suggested that 14 of the integrated specimens (67\%) were inserted into the host $\mathrm{X}$ gene in the forward direction, $12(57 \%)$ in the reverse direction, $5(24 \%)$ in both the forward and reverse directions, and $8(38 \%)$ had two HBV integration sites (data not shown). NCBI BLAST was used to identify HCC specimens displaying high homology to the nucleotide sequence of the HBV X gene, and the results suggested that $95.0-99.7 \%$ of specimens displayed high homology (data not shown).

$H B V$ integrates into ZBTB20. High throughput sequencing methods were used to analyse four normal liver tissues, five HCC tissues and six paracancerous tissues (not all 30 specimens 


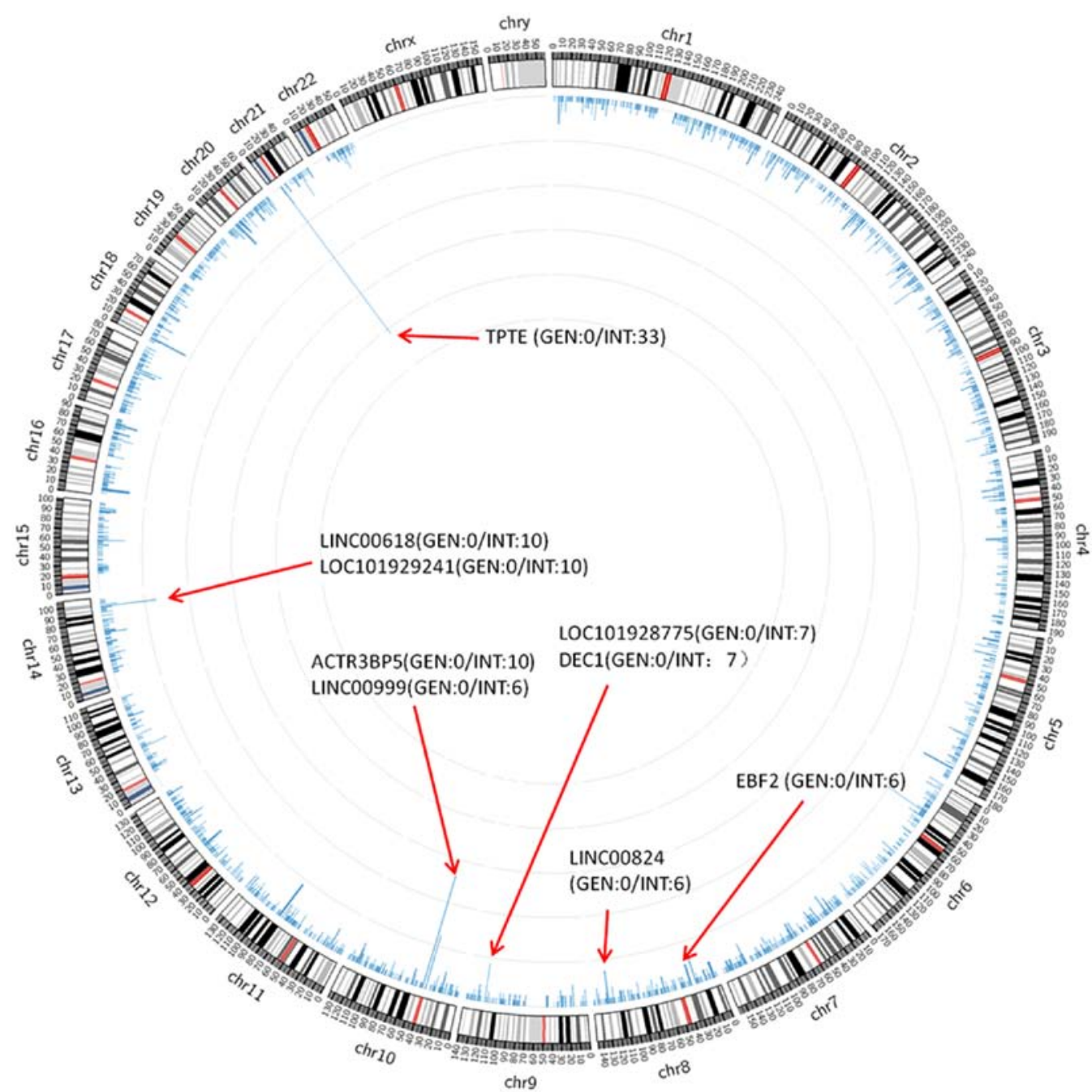

Figure 4. Distribution of integration sites in the human genome. The outermost circle represents the human genome. Blue columns indicate the integration (INT) sites and the column height indicates the integration frequency. Genes (GEN) with high frequency integration sites are annotated. TBTE, transmembrane phosphatase with tensin homology; LINC, long intergenic non-protein coding RNA; ACTR3BP5, ACTR3 pseudogene 5; DEC1, deleted in esophageal cancer 1; EBF2, EBF transcription factor 2; chr, chromosome; GEN, genes; INT, integration.

were used for high-throughput sequencing). The distribution of viral and host DNA integration sites are presented in Circos plots (Fig. 1). In total, 3,320 HBV integration sites were identified, including 718 in the normal liver tissues, 1,397 in the HCC tissues and 1,205 in the paracancerous tissues (Fig. 1A-C). The number of integration sites between the three tissue types was significantly different $(\mathrm{P}<0.05)$.

The integration sites in the HBV genome were scattered throughout the genome, and were notably enriched (Fig. 2A). Integration sites with high integration frequencies were concentrated in the 200-800 bp region (Fig. 2A). However, mutation sites with high frequencies were enriched in the 2,840-2,860 bp region (Figs. 2B and 3).

The integration of HBV into the human genome integration sites was analyzed, and the annotations with the highest integration site frequencies were transmembrane phosphatase with tensin homology (TPTE), long intergenic non-protein coding RNA (LINC)00618, LOC101929241, ACTR3 pseudogene 5 (ACTR3BP5), LINC00999, LOC101928775, deleted in oesophageal cancer 1 (DEC1), LINC00824, EBF transcription factor 2 (EBF2) and ZBTB20 (Fig. 4).
HBV integration sites were identified in the vicinity of ZBTB20: one in the downstream region; 38 in the intergenic region; 18 in the intronic region; one in the upstream region; one in the 3'-untranslated region (UTR); and one in the 5'-UTR (Table II).

ZBTB2O is upregulated in HCC tissues. The expression of ZBTB20 in HCC, paracancerous and normal control liver tissues was analyzed by western blotting (Fig. 5). The expression of ZBTB20 in tissues varied among the individuals, however; the overall trend was significantly increased expression in HCC tissues compared with normal control liver tissues, which displayed the lowest expression levels among the three tissue types (Fig. 5). Among the HCC specimens, higher ZBTB20 expression levels were observed in the HCC tissues with higher integration frequencies (T3, $53 \mathrm{HBV}$ DNA integrations vs. T1, $28 \mathrm{HBV}$ DNA integrations, as descripted in Fig. 5), suggesting that $\mathrm{HBV}$ integration frequency was related to the level of ZBTB20 expression. The results indicated that the expression of ZBTB20 was affected by the frequency of HBV integration. 
Table II. Zinc finger protein integration site statistics.

\begin{tabular}{llr}
\hline Gene & Location & Frequency \\
\hline ZBTB20 & Downstream & 1 \\
& Intergenic & 38 \\
& Intronic & 18 \\
& Upstream & 1 \\
& 3'-UTR & 1 \\
& 5'-UTR & 1 \\
\hline
\end{tabular}

ZBTB20, zinc finger and BTB domain containing 20; UTR, untranslated region.

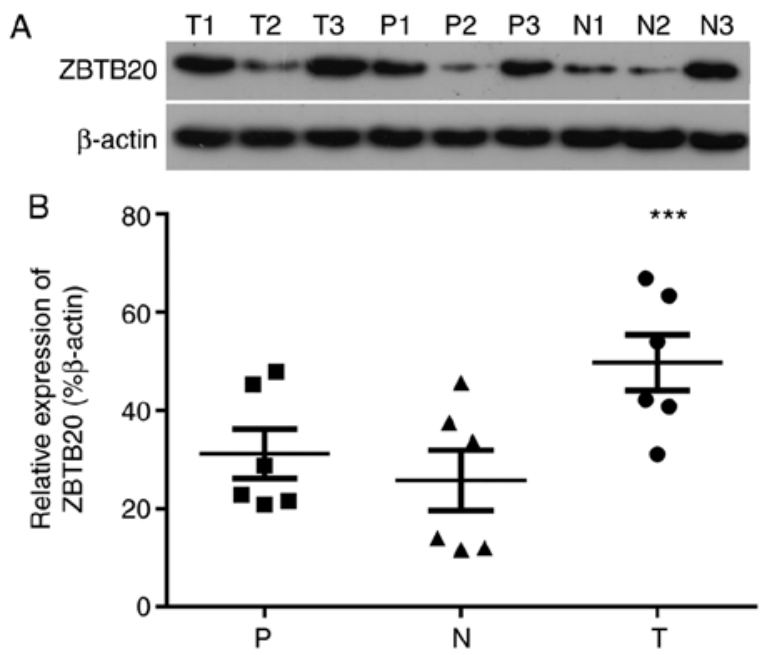

Figure 5. Expression of ZBTB20 in HCC tissues. Levels of ZBTB20 were (A) determined by western blot analysis and (B) quantified. The frequencies of HBV DNA integrations were: T1 displayed 28 HBV DNA integrations, T2 displayed no HBV integration and T3 displayed 53 HBV DNA integrations, suggesting that HBV DNA molecules integrated at a higher frequency in $\mathrm{T} 3$ compared with $\mathrm{T} 1{ }^{* * * *} \mathrm{P}<0.001$ vs. N. ZBTB20, zinc finger and BTB domain containing 20; T, HCC tissue; $\mathrm{P}$, paracancerous tissue; $\mathrm{N}$, normal liver tissue.

\section{Discussion}

HBV DNA host genome integration is an important cancer-inducing factor in HBV-associated HCC. Although the level of HBV DNA integration into host genes is random, a number of genes including TP53, PIK3CA, AXIN1 and DENG are associated with high frequency HBV integration (25). The integrated HBV fragment can act as an enhancer by upregulating the transcription level of genes adjacent to the integration site (26). HBV-Alu PCR allows HBV DNA integration sites to be separated; however, it can only detect human gene Alu fragments and integrated fragments near specific viral gene sequences (27). High-throughput sequencing technology can detect an increased number of integration sites and identify more integration regions compared with HBV-Alu-PCR. In the present study, $\mathrm{HCC}$ samples containing integration sites were selected by HBV-Alu-PCR, and HBV integration was further analyzed by high-throughput sequencing. The results suggested that $67 \%$ of the specimens displayed inte- gration into the host $\mathrm{X}$ gene in the forward direction, $57 \%$ in the reverse direction, 24\% in both the forward and reverse insertions, and $38 \%$ had two HBV integration sites. A total of 3,320 HBV virus integration breakpoints were identified, including 1,397 in HCC tissues, 1,205 in paracancerous tissues and 718 in normal liver tissues. Furthermore, the results suggested that HBV was highly integrated into TPTE, LINC00618, LOC101929241, ACTR3BP5, LINC00999, LOC101928775, DEC1, LINC00824, EBF2 and ZBTB20 in HCC tissues. Additionally, the HBV integration fragment displayed significant enrichment in the 200-800 bp region, and the mutation sites were specifically enriched in the $2,840-2,860$ bp region.

The zinc finger protein ZBTB20 contains an $\sim 100$ amino-acids long conserved BTB domain at the $\mathrm{N}$-terminus, which mediates interactions between proteins, as well as a $\mathrm{C}$-terminal $\mathrm{C} 2 \mathrm{H} 2$ zinc finger domain containing five conservative amino acids (28). The C-terminus of ZBTB20 can interact with DNA to regulate chromatin modifications and transcriptional activation or inhibition, and thus participate in a variety of cellular functions, including transcription regulation, cell proliferation, apoptosis, cell morphology, ion channels, collection and ubiquitin protein degradation $(29,30)$. In addition, ZBTB20 plays an important role in DNA damage and tumor development (31), and is widely expressed in malignant tumor cells of the hematopoietic system (32). ZBTB20 is also a key transcription inhibitor of the hepatic AFP gene inactivation after birth (33). Previous studies have reported that liver AFP expression in hepatic specific ZBTB20 knockout mice is high, but there is no obvious internal relationship between the expression of AFP in liver cells and cell proliferation (21). It has also been reported that the expression of ZBTB20 is upregulated in clinical HCC cells and displays a positive regulatory effect on hepatocyte proliferation (29). HCC with high ZBTB20 expression has been associated with increased malignancy, which manifests as metastasis and post-operative recurrence with a low 5-year survival rate (29). It has also been reported that ZBTB20 expression is closely related to the prognosis of HCC (29). In the present study, ZBTB20 was upregulated in HCC tissues and HBV integrated into ZBTB20. Moreover, the expression of ZBTB20 in tumor tissues was associated with HBV integration frequency. However, a relationship between clinical characteristics and the frequency of HBV integration or ZBTB2 expression was not identified, therefore, further investigation is required.

In summary, the present study suggested that HBV DNA integration and ZBTB20 expression are associated, and may promote the occurrence and development of HCC.

\section{Acknowledgements}

Not applicable.

\section{Funding}

The present study was supported by the Nature Science Fund of the Zhejiang Provincial of China (grant no. LY16H030001) and the Medical Science Fund of Taizhou of China (grant no. 2015A33259). 


\section{Availability of data and materials}

The datasets used and/or analyzed during the current study are available from the corresponding author on reasonable request.

\section{Authors' contributions}

$\mathrm{ZH}$ and $\mathrm{QC}$ contributed to the conception or design of the study; ZH, JZ, JM, HZ and QC the acquisition, analysis or interpretation of data for the study; ZH, JZ, JM, HZ and CQ drafted the manuscript, revised it and checked the final version. All authors reviewed and approved the final manuscript.

\section{Ethics approval and consent to participate}

The present study was approved by the Ethics Committee of Taizhou Central Hospital (approval no. T13010132Y). All participants provided written informed consent.

\section{Patient consent for publication}

Not applicable.

\section{Competing interests}

The authors declare that they have no competing interests.

\section{References}

1. Singal AG, Li X, Tiro J, Kandunoori P, Adams-Huet B, Nehra MS and Yopp A: Racial, social, and clinical determinants of hepatocellular carcinoma surveillance. Am J Med 128: 90.e91-90.e97, 2015.

2. Zeng Y: Advances in mechanism and treatment strategy of cancer. Cell Mol Biol 64: 1-3, 2018.

3. Younossi ZM, Stepanova M, Saab S, Ahmed A, Lam B, Srishord M, Venkatesan C, Wai H and Henry L: The impact of viral hepatitis related hepatocellular carcinoma to post transplant outcomes. J Viral Hepat 23: 53-61, 2016.

4. Chisari FV and Ferrari C: Hepatitis B virus immunopathogenesis. Annu Rev Immunol 13: 29-60, 1995.

5. Wang M, Xi D and Ning Q: Virus-induced hepatocellular carcinoma with special emphasis on HBV. Hepatol Int 11: 171-180, 2017.

6. Zeng Y, Yao X, Liu X, He X, Li L, Liu X, Yan Z, Wu J and Fu BM: Anti-angiogenesis triggers exosomes release from endothelial cells to promote tumor vasculogenesis. J Extracell Vesicles 8: 1629865, 2019.

7. Lupberger J and Hildt E: Hepatitis B virus-induced oncogenesis. World J Gastroenterol. 13: 74 81, 2007.

8. Hino O, Ohtake K and Rogler CE: Features of two hepatitis B virus (HBV) DNA integrations suggest mechanisms of HBV integration. J Virol 63: 2638-2643, 1989.

9. Maddrey WC: Hepatitis B: an important public health issue. J Med Virol 61: 362-366, 2000.

10. Shlomai A, de Jong YP and Rice CM: Virus associated malignancies: The role of viral hepatitis in hepatocellular carcinoma. Semin Cancer Biol 26: 78-88, 2014.

11. Dandri M and Locarnini S: New insight in the pathobiology of hepatitis B virus infection. Gut 61 (Suppl 1): i6-i17, 2012.

12. Minami M: Integration of hepatitis B virus genome into the host gene: Its significance to hepatocarcinogenesis. Nihon Rinsho 73 (Suppl 9): 409-413, 2015 (In Japanese).

13. Jiang S, Yang Z, Li W, Li X, Wang Y, Zhang J, Xu C, Chen PJ, Hou J, McCrae MA, et al: Re-evaluation of the carcinogenic significance of hepatitis B virus integration in hepatocarcinogenesis. PLoS One 7: e40363, 2012.
14. Edman JC, Gray P, Valenzuela P, Rall LB and Rutter WJ: Integration of hepatitis $B$ virus sequences and their expression in a human hepatoma cell. Nature 286: 535-538, 1980.

15. Tu T, Budzinska MA, Shackel NA and Urban S: HBV DNA Integration: Molecular Mechanisms and Clinical Implications. Viruses 9: 9, 2017.

16. Yang L, Ye S, Zhao X, Ji L, Zhang Y, Zhou P, Sun J, Guan Y, Han Y, Ni C, et al: Molecular Characterization of HBV DNA Integration in Patients with Hepatitis and Hepatocellular Carcinoma. J Cancer 9: 3225-3235, 2018.

17. Liu S, Koh SS and Lee CG: Hepatitis B Virus X Protein and Hepatocarcinogenesis. Int J Mol Sci 17: 940, 2016.

18. Sung WKZH, Zheng H, Li S, Chen R, Liu X, Li Y, Lee NP, Lee WH, Ariyaratne PN, Tennakoon C, et al: Genome-wide survey of recurrent HBV integration in hepatocellular carcinoma. Nat Genet 44: 765-769, 2012.

19. Kan H, Huang Y, Li X, Liu D, Chen J and Shu M: Zinc finger protein ZBTB20 is an independent prognostic marker and promotes tumor growth of human hepatocellular carcinoma by repressing FoxO1. Oncotarget 7: 14336-14349, 2016.

20. Yao M, Yao DF, Bian YZ, Wu W, Yan XD, Yu DD, Qiu LW, Yang JL, Zhang HJ, Sai WL, et al: Values of circulating GPC-3 mRNA and alpha-fetoprotein in detecting patients with hepatocellular carcinoma. Hepatobiliary Pancreat Dis Int 12: 171-179, 2013.

21. Zhang H, Shi JH, Jiang H, Wang K, Lu JY, Jiang X, Ma X, Chen YX, Ren AJ, Zheng J, et al: ZBTB20 regulates EGFR expression and hepatocyte proliferation in mouse liver regeneration. Cell Death Dis 9: 462, 2018

22. Xie Z, Zhang H, Tsai W, Zhang Y, Du Y, Zhong J, Szpirer C, Zhu M, Cao X, Barton MC, et al: Zinc finger protein ZBTB20 is a key repressor of alpha fetoprotein gene transcription in liver. Proc Natl Acad Sci U S A 105: 10859-10864, 2008.

23. World Health Organization (WHO): Guidelines for the prevention, care and treatment of persons with chronic hepatitis B infection. WHO, Geneva, 2015.

24. Masaki H, Takashi A, Naoto T, Kuwana Y, Shigemoto Y, Miyazaki S, Suzuki Y and Sugawara H: Genome Information Broker for Viruses (GIB-V): database for comparative analysis of virus genomes. Nucleic Acids Res 35 (Database issue): D339-D342, 2007.

25. Zucman-Rossi J and Laurent-Puig P: Genetic diversity of hepatocellular carcinomas and its potential impact on targeted therapies. Pharmacogenomics 8: 997-1003, 2007.

26. Guerrero RB and Roberts LR: The role of hepatitis B virus integrations in the pathogenesis of human hepatocellular carcinoma. J Hepatol 42: 760-777, 2005.

27. Murakami Y, Saigo K, Takashima H, Minami M, Okanoue T, Bréchot $\mathrm{C}$ and Paterlini-Bréchot $\mathrm{P}$ : Large scaled analysis of hepatitis B virus (HBV) DNA integration in HBV related hepatocellular carcinomas. Gut 54: 1162-1168, 2005.

28. Zhang W, Mi J, Li N, Sui L, Wan T, Zhang J, Chen T and Cao X: Identification and characterization of DPZF, a novel human $\mathrm{BTB} / \mathrm{POZ}$ zinc finger protein sharing homology to BCL-6. Biochem Biophys Res Commun 282: 1067-1073, 2001.

29. Wang Q, Tan YX, Ren YB, Dong LW, Xie ZF, Tang L, Cao D, Zhang WP, Hu HP and Wang HY: Zinc finger protein ZBTB20 expression is increased in hepatocellular carcinoma and associated with poor prognosis. BMC Cancer 11: 271, 2011.

30. Nagao M, Ogata T, Sawada Y and Gotoh Y: Zbtb20 promotes astrocytogenesis during neocortical development. Nat Commun 7: 11102, 2016.

31. Chevrier S and Corcoran LM: BTB-ZF transcription factors, a growing family of regulators of early and late B-cell development. mmunol Cell Biol 92: 481-488, 2014.

32. Maeda T: Regulation of hematopoietic development by ZBTB transcription factors. Int J Hematol 104: 310-323, 2016.

33. Cao D, Ma X, Cai J, Luan J, Liu AJ, Yang R, Cao Y, Zhu X, Zhang $\mathrm{H}$, Chen YX, et al: ZBTB20 is required for anterior pituitary development and lactotrope specification. Nat Commun 7: 11121, 2016.

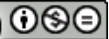

This work is licensed under a Creative Commons Attribution-NonCommercial-NoDerivatives 4.0 International (CC BY-NC-ND 4.0) License. 